\title{
Correction to: Association between HIV infection and hypertension: a global systematic review and meta-analysis of cross-sectional studies
}

Katherine Davis ${ }^{1 *}$, Pablo Perez-Guzman ${ }^{1}$, Annika Hoyer ${ }^{2}$, Ralph Brinks ${ }^{3}$, Edward Gregg ${ }^{4}$, Keri N. Althoff , Amy C. Justice ${ }^{6}$, Peter Reiss ${ }^{7,8}$, Simon Gregson ${ }^{1,9}$ and Mikaela Smit ${ }^{1}$

Correction to: BMC Med 19, 105 (2021)

https://doi.org/10.1186/s12916-021-01978-7

The original article [1] contains an error in Table 1 whereby it is stated that the study period of the observational study by Guaraldi et al. was 2002-2019.

This should instead state 2002-2009.

\begin{abstract}
Author details
'MRC Centre for Global Infectious Disease Analysis, Department of Infectious Disease Epidemiology, St Mary's Campus, Imperial College London, London W2 1PG, UK. ${ }^{2}$ Department of Statistics, Ludwig-Maximilians-University Munich, Munich, Germany. ${ }^{3}$ Hiller Research Unit of Rheumatology, University Hospital Duesseldorf, Duesseldorf, Germany. ${ }^{4}$ Department of Epidemiology and Biostatistics, Imperial College London, London, UK. ${ }^{5}$ Department of Epidemiology, Johns Hopkins University, Baltimore, MD, USA. 'Schools of Medicine and Public Health, Yale University, New Haven, CT, USA. ${ }^{7}$ Department of Global Health, Amsterdam University Medical Centers, University of Amsterdam and Amsterdam Institute for Global Health and Development, Amsterdam, Netherlands. ${ }^{8}$ HIV Monitoring Foundation, Amsterdam, Netherlands. ${ }^{9}$ Biomedical Research and Training Institute, Harare, Zimbabwe.
\end{abstract}

Published online: 08 September 2021

\section{Reference}

1. Davis K, et al. Association between HIV infection and hypertension: a global systematic review and meta-analysis of cross-sectional studies. BMC Med. 2021;19:105 https://doi.org/10.1186/s12916-021-01978-7.

The original article can be found online at https://doi.org/10.1186/s12916 021-01978-7.

* Correspondence: K.davis18@imperial.ac.uk

'MRC Centre for Global Infectious Disease Analysis, Department of Infectious Disease Epidemiology, St Mary's Campus, Imperial College London, London W2 1PG, UK

Full list of author information is available at the end of the article

(C) The Author(s). 2021 Open Access This article is licensed under a Creative Commons Attribution 4.0 International License, which permits use, sharing, adaptation, distribution and reproduction in any medium or format, as long as you give appropriate credit to the original author(s) and the source, provide a link to the Creative Commons licence, and indicate if changes were made. The images or other third party material in this article are included in the article's Creative Commons. licence, unless indicated otherwise in a credit line to the material. If material is not included in the article's Creative Commons licence and your intended use is not permitted by statutory regulation or exceeds the permitted use, you will need to obtain permission directly from the copyright holder. To view a copy of this licence, visit http://creativecommons.org/licenses/by/4.0/ The Creative Commons Public Domain Dedication waiver (http://creativecommons.org/publicdomain/zero/1.0/) applies to the data made available in this article, unless otherwise stated in a credit line to the data. 